Research Article

www.jestr.org

\title{
Adaptive Controller for Drive System PMSG in Wind Turbine
}

\author{
Gnanambal $^{1}$, G.Balaji $^{*}, 2$ and M.Abinaya ${ }^{2}$ \\ ${ }^{1}$ Department of Electrical and Electronics Engineering, Govt. College of Engineering, Salem - 636 011, Tamil Nadu, India. \\ ${ }^{2}$ Department of Electrical and Electronics Engineering, Paavai Engineering College, Namakkal - 637 018, Tamil Nadu, India.
}

Received 8 May 2014; Accepted 11 July 2014

\begin{abstract}
This paper proposes adaptive Maximum Power Point Tracking (MPPT) controller for Permanent Magnet Synchronous Generator (PMSG) wind turbine and direct power control for grid side inverter for transformer less integration of wind energy. PMSG wind turbine with two back to back voltage source converters are considered more efficient, used to make real and reactive power control. The optimal control strategy has introduced for integrated control of PMSG Maximum Power Extraction, DC link voltage control and grid voltage support controls. Simulation model using MATLAB Simulink has developed to investigate the performance of proposed control techniques for PMSG wind turbine steady and variable wind conditions. This paper shows that the direct driven grid connected PMSG system has excellent performances and confirms the feasibility of the proposed techniques. While the wind turbine market continues to be dominated by conventional gear-driven wind turbine systems, the direct drive is attracting attention. PM machines are more attractive and superior with higher efficiency and energy yield, higher reliability, and power-to-weight ratio compared with electricity-excited machines.
\end{abstract}

Keywords: DC-Link Voltage Control, Direct Power Control, Grid Voltage Support Control, Maximum Wind Power Extraction, Optimal Control, Permanent Magnet Synchronous Generator (PMSG) Wind Turbine.

\section{Introduction}

Today's most promptly growing renewable energy source is wind energy. A wind turbine operates see the rat a fix edor variable speed[1]. Developing new megawatt scale windturbines based on variable-speed operation with pitch control using either a permanent magnet synchronous generator (PMSG) or a doubly fed induction generator is preferred by most of the manufacturers (DFIG) [2].

Though the variable speed wind turbine with a multi-pole PMS Gand full-scale/ fully controllable voltage source converters (VSCs) is considered to bee minent enough, it is not popular wind turbine concept [3]. The advantages of such a PMSG configuration are 1)gearless construction [4]; 2) elimination of adc excitation system [5]; 3)maximum wind power extraction and grid interface; and 4) ease in accomplishing fault - ride through and grid support [6]. There fore, the efficiency and reliability of a VSC-based PMSG windturbine is assessed to be higher than that of a DFIG wind turbine[7]. Due to the intensified grid codes, a PMSG wind turbine with full VSC-based insulated gate bipolar transistor (IGBT) converters are becoming more and more enhanced by the wind power industry [3]-[7].

At the present time, however, commercial PMSG technology mainly uses a passive rectifier followed by an IGBT inverter [8]-[11]. The highly efficient vector controlled technology for a PMSG wind turbine that uses a full voltage - source IGBTconverter configuration is still under

\footnotetext{
*E-mail address: rahullaagi@gmail.com

ISSN: 1791-2377 @ 2014 Kavala Institute of Technology. All rights reserved.
}

investigation [12]-[14] and not widely adopted by the wind power industry. The direct-current vector control technology is a vector control technology that has been developed recently to control the synchronous generator only inavariable - speed PMSG wind turbine[15], [16] and for control of a VSC - based HVDC system [17]. Compared to the conventional vector control strategies, direct - current vector control has illustrated many advantages in those applications, such as enhanced system stability, reliability, and efficiency. But it is not clear whether the direct-current vector control can beem ployed in a PMSG wind turbine for control of both PMSG machine - and grid- side converters (GSCs), and how the PMSG system will be have in the integrated environment for multiple PMSG control purposes.

This paper presents mechanisms for optimal control of a PMSG wind turbine system under a direct-current $d q$ vector control configuration. Based on the proposed control structure, the overall control functions of a PMSG system are developed, including maximum power extraction control, dclink voltage control, reactive power control, and grid voltage support control.

\section{Model of PMSG and Concept of Direct Power Control}

In the study, the shaft of a significantly larger turbine is coupled with PM generator. The speed of the PM generator will not be affected by the load power. In other words, the output frequency won't change during operation, despite heavy load or light load is connect. Thissimplifies the control system design. The dynamic d-q model is used for 
the PMG to eliminate the time-varying inductances. With the Park transformation the variables in a-b-c coordinates are transformed to $\mathrm{d}-\mathrm{q}$ coordinates, as shown in the following equation.

$$
\begin{gathered}
{\left[\begin{array}{l}
i_{d} \\
i_{q} \\
i_{0}
\end{array}\right]=} \\
\sqrt{\frac{2}{3}}\left[\begin{array}{ccc}
\sin \omega t & \sin \left(\omega t-\frac{2}{3} \pi\right) & \sin \left(\omega t+\frac{2}{3} \pi\right) \\
\cos \omega t & \cos \left(\omega t-\frac{2}{3} \pi\right) & \cos \left(\omega t+\frac{2}{3} \pi\right) \\
\frac{1}{2} & \frac{1}{2} & \frac{1}{2}
\end{array}\right]\left[\begin{array}{c}
i_{a} \\
i_{b} \\
i_{c}
\end{array}\right]
\end{gathered}
$$

The basic concept of direct control of active and reactive powers can be understood from the phasor diagrams based on the equivalent circuit of the permanent magnet synchronous generator as shown in Fig. 1. From the phasor diagram in Fig. 2 it is noted that the Component $i_{s q}$ of the stator current has to be controlled in order to control the stator active power $P_{s}$ and $i_{s d}$ has to be controlled to control the stator reactive power $Q_{s}$. This is achieved in turn by controlling the rotor currents $i_{r q}$ and $i_{r d}$, respectively, in conventional field oriented control strategy.

Wound rotor in a synchronous generator and the stator in a PMG have similar structure. In addition there is no difference between the back EMF produced by a permanent magnet and that produced by an excited coil. The mathematical model of a PMG can be derivedfrom the model of a synchronous generator. The only difference is the equations of the damper windings and the field current dynamics can be removed. Finally, the equivalent circuits of $\mathrm{d}$-axis and q-axis of a permanent magnet synchronous generator are illustrated in Figure 1.

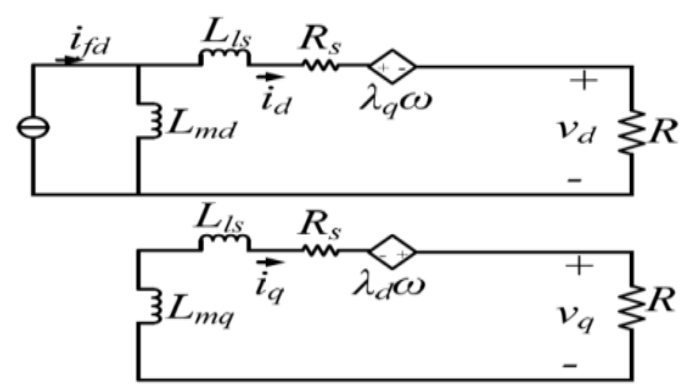

Fig. 1.Equivalent Circuit of The Permanent Magnet Synchronous Generator in d-q Axis

The state-space equations for PMG are given by.

$V_{d}=-R_{s} i_{d}-\omega \lambda_{q}+\frac{d \lambda_{d}}{d t}$

$V_{q}=-R_{s} i_{q}-\omega \lambda_{d}+\frac{d \lambda_{q}}{d t}$

$\lambda_{d}=-\left(L_{l s}+L_{m d}\right) i_{d}+L_{m d} i_{f d}$

$\lambda_{q}=-\left(L_{l s}+L_{m q}\right) i_{q}$

$\lambda_{m}=L_{m d} i_{f d}$

The currents $i_{d}, i_{q}$ and the voltages $V_{d}, V_{q}$ represent the stator $\mathrm{d}$ and q currents and voltages respectively. $L_{l s}$ and $R_{s}$ are present the armature resistance and leakage inductance. $L_{m d}$ and $L_{m q}$ represent the $\mathrm{d}$ and q magnetizing inductances. $\lambda_{d}$ and $\lambda_{q}$ represent the magnetic flux in the d-q axes. And $\omega$ represents the electrical angular velocity.

The two-axes of PMSM stator windings are modelled such that to have equal turns per phase.The rotor flux of the PMSM is assumed to be concentrated along the d-axis while there is zero flux along the q-axis, and the machine core losses are assumed to be negligible while rotor flux is assumed to be stable at the given operating point.

The rotor frame of reference is chosen because the position of the rotor magnets determines the stator voltages and currents independently, the instantaneous induced emfs and subsequently the stator currents and torque of the machine. When the rotor reference frames are considered, it means the equivalent $\mathrm{q}$ and $\mathrm{d}$ axis stator windings are transformed to the reference frames which are revolving at rotor speed. The consequence is that there are zero speed differentials between the rotor and stator magnetic fields and the stator $\mathrm{q}$ and $\mathrm{d}$ axis windings will have a fixed phase relationship with the rotor magnet axis.

The stator flux-linkage equations are

$V_{q s}^{r}=R_{q} i_{q s}^{r}+P \lambda_{q s}^{r}+\omega_{r} \lambda_{d s}^{r}$

$V_{d s}^{r}=R_{d} i_{d s}^{r}+P \lambda_{d s}^{r}-\omega_{r} \lambda_{q s}^{r}$

Where $R_{q}$ and $R_{d}$ are the quadrature and direct axis winding resistances, which are equal (and hereafter referred to as $R_{S}$ ), and the $\mathrm{q}$ and $\mathrm{d}$ axes stator flux linkages in the rotor reference frames are

$\lambda_{q s}^{r}=L_{s} i_{q s}^{r}+L_{m} i_{q r}^{r}(9)$
$\lambda_{q s}^{r}=L_{s} i_{q s}^{r}+L_{m} i_{q r}^{r}(10)$

But the self-inductances of the stator $\mathrm{q}$ and $\mathrm{d}$ axes windings are equal to $L_{s}$ only when the rotor magnets have an arc of electrical $180^{\circ}$. When a stator winding is in alignment with the rotor magnet axis, the reluctance of the path is maximum the magnet reluctance is almost the sameair gap reluctance, and hence its inductance is the lowest at this time. The inductance is then referred as the direct-axis inductance $L_{d}$.

The inductance of the q axis winding is $L_{q}$. As the rotor magnets and the stator $\mathrm{q}$ and $\mathrm{d}$ axis windings are fixed in space, the winding inductance does not change in rotor reference frames. In order to compute the stator flux linkages in the $\mathrm{q}$ and $\mathrm{d}$ axes, the currents in the rotor and stator are required. The permanent magnet excitation can be modelled as a constant current source, $i_{f r}$. The rotor flux is along the $\mathrm{d}$ axis, so the $\mathrm{d}$ axis rotor current is $i_{f r}$. By assumption, the $\mathrm{q}$ axis current in the rotor is zero, because there is no flux along this axis in the rotor. Then the flux linkages are written as

$\lambda_{q s}^{r}=L_{q} i_{q s}^{r}$

$\lambda_{d s}^{r}=L_{d} i_{d s}^{r}+L_{m} i_{f r}$

Where $L_{m}$ is the mutual inductance between the stator winding and rotor magnet, Substituting these flux linkages into the stator voltage equations gives the stator equations: 
$\left[\begin{array}{c}V_{q s}^{r} \\ V_{d s}^{r}\end{array}\right]=\left[\begin{array}{cc}R_{q}+L_{q} p & \omega_{r} L_{d} \\ -\omega_{r} L_{q} & R_{d}+L_{d} p\end{array}\right]\left[\begin{array}{c}i_{q s}^{r} \\ i_{d s}^{r}\end{array}\right]+\left[\begin{array}{c}\omega_{r} L_{m} i_{f r} \\ 0\end{array}\right]$

The electromagnetic torque is given by

$T_{e}=\frac{3}{2} \frac{P}{2}\left\{\lambda_{d s}^{r} \lambda_{q s}^{r}-\lambda_{q s}^{r} \lambda_{d s}^{r}\right\}$

Which, upon substitution of the flux linkages in terms of the inductances and currents,

$T_{e}=\frac{3}{2} \frac{P}{2}\left\{\lambda_{a f} i_{q s}^{r}+\left(L_{d}-L_{q}\right) i_{q s}^{r} i_{d s}^{r}\right\}$

Where the rotor flux linkages that link the stator are

$\lambda_{a f}=L_{m} i_{f r}$

The rotor flux linkages are considered constant except for temperature effects. The residual flux density is reduced by the temperature sensitivity of the magnets and hence, the flux linkages with increasing temperature.The electromagnetic torque is positive for the monitoring action, if $\delta$ is positive. The rotor flux linkages $\lambda_{a f}$ are positive. Then the phasor diagram for an arbitrary torque angle $\delta$ is shown in fig. 2.

Where,

$i_{q s}^{r}=$ Torque - producing component of stator current $=i_{T}$ $i_{d s}^{r}=$ Flux - producing component of stator current $=i_{f}$ and the torque angle is given by, $\theta_{T}=\delta(17)$

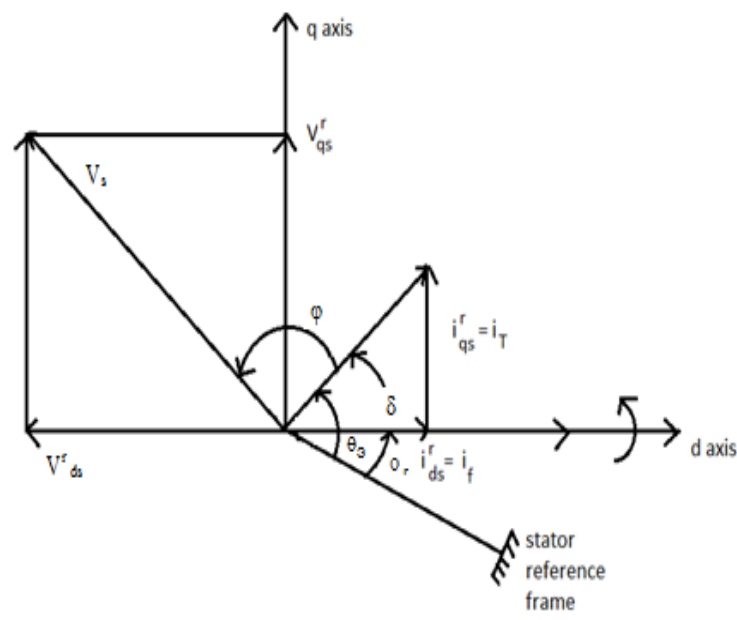

Fig.2. Phasor diagram of the PM synchronous machine

The mutual flux linkage is the resultant of the rotor flux linkages and stator flux linkages. It is then given as

$\lambda_{m}=\sqrt{\left(\lambda_{a f}+L_{d} i_{d s}^{r}\right)^{2}+\left(L_{q} i_{q S}^{r}\right)^{2}}$ (Wb-Turn)

If $\delta$ is greater than $\pi / 2, i_{d s}^{r}$ becomes negative, the resultant mutual flux linkages decrease. If $\delta$ is negative with respect to the rotor or mutual flux linkages, the machine works as a generator[26].

\section{Electrical Systems and Integrated Controls}

A VSC-based PMSG wind turbine consists mainly of three parts: a wind turbine drive train, a PMSG, and two back-to back VSCs (see Fig. 3). In the turbine drive train, the rotor blades of the wind turbine catch wind energy that is then transferred to the generator. The generator, converts mechanical energy into electrical energy, is a standard permanent magnet synchronous machine with its stator windings connected to the grid through a frequency converter. The frequency converter is built by two currentregulated voltage-source pulse width modulation (PWM) converters: an MSC and a GSC, with a de voltage link in between.

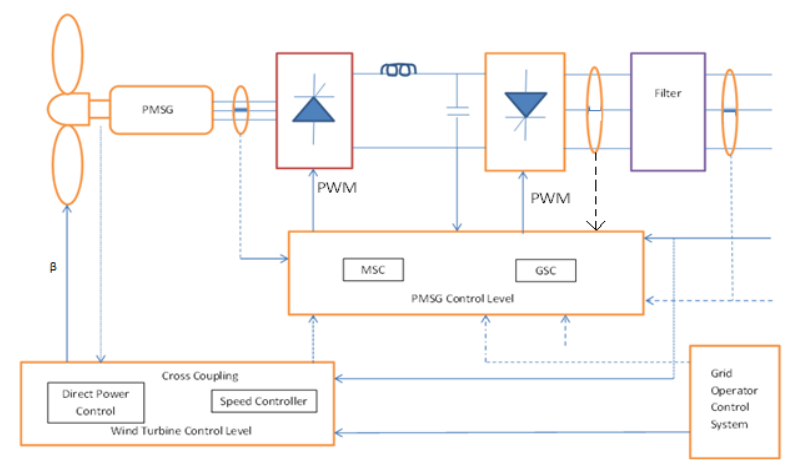

Fig. 3. Configuration of a PMSG Wind Turbine with Adaptive MPPT Controller and DPC Method PMSG

The control of the PMSG system has three levels: the generator level, the wind turbine level, and the wind power plant level (see Fig. 1) [17], [20]. At the generator level, each of the two VSCs (see Fig. 1) is controlled through decoupled $d q$ vector control approaches in the conventional technology. The MSC controls the PMSG to achieve the following goals: maximum energy extraction from the wind and/or compliance with a control demand from the wind power plant control centre. The GSC maintains a constant dc-link voltage and adjusts reactive power absorbed from the grid by the converter. At the wind turbine level, there is a speed controller and a power limiting controller. At low wind speeds, the speed controller gives a power or torque reference to the MSC controller based on the principle of maximum energy capture. The power limiting controller increases or decreases the pitch angle of wind turbine blades to prevent the turbine from going over the rated power at high wind speeds. At the wind power plant level, the power production of the entire plant is determined based on the grid requirements. The central control system sends out reference power signals to each individual wind turbine according to a grid need, while the local turbine control system ensures that the reference power signal sent by the central control system is reached [20].

\subsection{Direct Power Control of MSC}

The conventional power control method for the MSC has a nested-loop structure consisting of a faster inner current loop and a slower outer loop as shown by Fig. 4, in which the $q$ axis loop is for wind turbine speed or torque control and the $d$-axis loop is for other control purposes. The control strategy of the inner current loop is developed as

$v_{s d}=-\left(R_{s} i_{s d}+L_{d} \frac{d i_{s d}}{d t}\right)-\omega_{e} L_{q} i_{s q}$ 
$v_{s q}=-\left(R_{s} i_{s d}+L_{d} \frac{d i_{s d}}{d t}\right)$

Where the item in the bracket of (19) and (20) is treated as the state equation between the voltage and current in the $d$ and $q$-loop, and the other items are treated as compensation terms. This treatment assumes that $v_{s d}$ in (19) has no major influence on $i_{s q}$ and $v_{s q}$ that in (20) has no significant effect on $i_{s d}$.

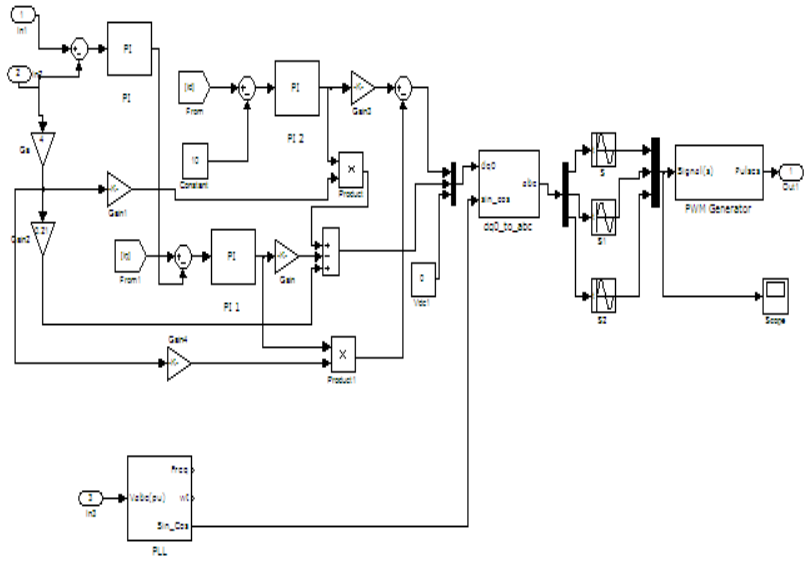

Fig.4. Direct power control structure in MSC

But this assumption is inadequate as explained as follows. The final control voltages $v_{s d}$ and $v_{s q}$, linearly proportional to the converter output voltages $v_{s d}$ and $v_{s d}$, include the $d$ - and $q$-axis voltages $v_{s d}$ and $v_{s q}$ generated by the current-loop controllers plus the compensation terms as shown by (21). Hence, the conventional control configuration intends to regulate $i_{s d}$ and $i_{s q}$ using $v_{s d}$ and $v_{s q}$, respectively. But, according to derived torque equation, the $d$-axis voltage is only effective for $i_{s q}$ or torque control, and the $q$-axis voltage is only effective for $i_{s q}$ control

$v_{s d}^{*}=v_{s d}^{\prime}-\omega_{e} L_{q} i_{s q}, v_{s q}^{*}=v_{s q}^{\prime}+\omega_{e} L_{d} i_{s d}+\omega_{e} \psi_{f}$

\subsection{Direct-Power Control of GSC}

The schematic of the GSC is shown in Fig. 5, in which the dc link capacitor is on the left and a three-phase voltage source, representing the voltage at the point of common coupling (PCC) of the ac system, is on the right. In the $d q$ reference frame, the voltage balance across the grid filter is

$\left[\begin{array}{l}v_{d 1} \\ v_{q 1}\end{array}\right]=R_{f}\left[\begin{array}{l}i_{d} \\ i_{q}\end{array}\right]+L_{f} \frac{d}{d t}\left[\begin{array}{l}i_{d} \\ i_{q}\end{array}\right]+\omega_{s} L_{f}\left[\begin{array}{c}-i_{q} \\ i_{d}\end{array}\right]+\left[\begin{array}{l}v_{d} \\ v_{q}\end{array}\right]$

Where $\omega_{s}$ is the angular frequency of the grid voltage, $L_{f}$ and $R_{f}$ are the inductance and resistance of the grid filter, respectively, $v_{d}, v_{q}, v_{d 1}$ and,$v_{q 1}$ represent the $d$ - and $q$ axis components of the PCC voltage and GSC output voltage, respectively, and, $i_{d}$ and $i_{q}$ represent the $d$ - and $q$ axis components of the current flowing between the GSC and the ac system.

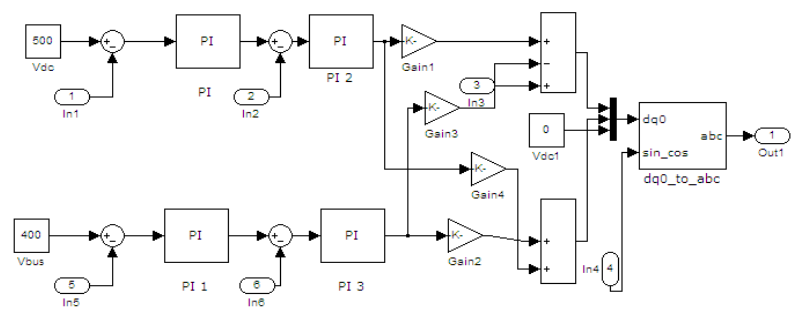

Fig.5. Direct power control structure in GSC

The conventional power control method for the GSC has a nested-loop structure consisting of a faster inner current loop and a slower outer loop as shown by Fig. 3 in which the $d$-axis loop is used for dc-link voltage control, and the $q$-axis loop is used for reactive power or grid voltage support control. The control strategy of the inner current loop is developed by rewriting (22) as

$v_{d 1}=\left(R_{f} i_{d}+L_{f} \cdot \frac{d_{i d}}{d t}\right)-\omega_{s} L_{f} i_{q}+v_{d}$

$v_{q 1}=\left(R_{f} i_{q}+L_{f} \cdot \frac{d_{i q}}{d t}\right)+\omega_{s} L_{f} i_{d}$

in which the item in the bracket of (23) and (24) is treated as the state equation between the voltage and current on $d$ - and $q$-axis loops, and the other items are treated as compensationterms. This treatment assumes that $v_{d 1}$ in (23) has no major influence on $i_{q}$, and $v_{q 1}$ in (24) has no significant impact on $i_{d}$.

However, this assumption conflicts with the GSC power control relations. The $d$-axis voltage is only effective for reactive power or $i_{q}$ control, and the $q$-axis voltage is only effective for active power or $i_{d}$ control.

$v_{d 1}^{\prime}=v_{d}^{\prime}-\omega_{s} L_{f} i_{q}+v_{d}, v_{q 1}^{\prime}=v_{q}^{\prime}+\omega_{s} L_{f} i_{d}$

\section{Maximum Power Point Tracking}

This is the base of the well-known Maximum Power Point Tracking (MPPT) from the prior treatment of the wind turbine model it can be appreciated that in order to extract the maximum amount of power from the incident wind, $C_{p}$ should be maintained at a maximum. In order to achieve this objective, it can be appreciated from Fig. 6 that the speed of the generator rotor must be optimized according to instantaneous wind speed.

In wind generator applications capturing the maximum available wind power is essential. Regarding that, it has been shown that variable-speed (VS) configurations generate more total annual energy at any wind speed than constant speed configurations becoming more and more attractive in low power applications.VS configurations the WG's rotating speed is changed guiding the aerodynamic system to operate at the maximum power point (MPP) for every wind speed. The latter is usually achieved through the generator's load variation by means of power converters.

The amount of power output from a wind energy conversion system (WECS) depends upon the accuracy with which the peak power points are tracked by the maximum power point tracking(MPPT) controller of the WECS control system irrespective of the type of generator used.This study provides a review of past and present MPPT controllers used 
for extracting maximum power from the WECS using PMSG.

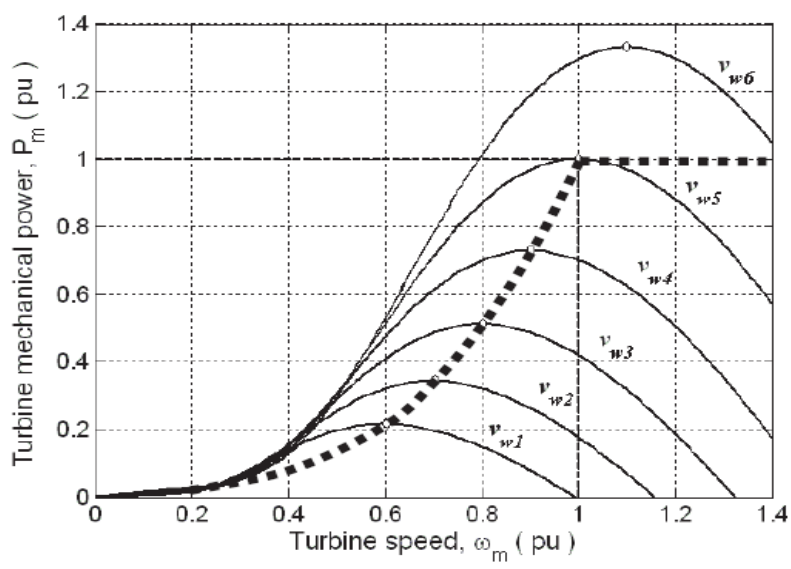

Fig. 6.Wind Turbine Characteristic of the Variable Speed PMSG.

The above shows turbine mechanical power as a function of rotor speed at various wind speeds. The power for a certain wind speed is maximum at a certain value of rotor speed called optimum rotor speed. This is the speed which corresponds to optimum tip speedratio. In order to have maximum possible power, the turbine should always operateatoptimum tip speed ratio. This is possible by controlling the rotational speed of the turbine so that it alwaysrotates at the optimum speed of rotation.

\subsection{MPPT Control Methods for PMSG Based WECS}

Permanent Magnet Synchronous Generator is preferred more and more in developing newdesigns because of higher efficiency, high power density, availability of high-energy Permanent magnet material at reasonable price, and possibility of smaller turbine diameter in direct drive applications. Presently, a lot of research efforts are directed towards designing of WECS which is reliable, having low wear and tear, compact, efficient, having low noise and maintenance cost; such a WECS is realisable in the form of a direct drivePMSG wind energy conversion system.

The power electronics converter configurations most commonly used for PMSG WECS are shown in Fig. 7.

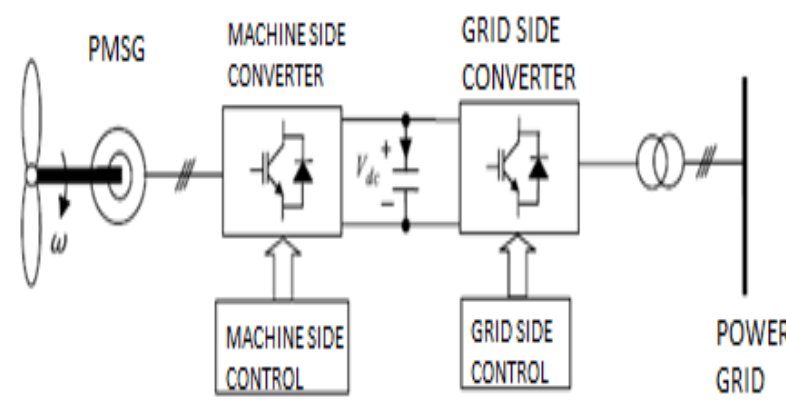

Fig.7. PMSG wind energy conversion systems

Depending upon the power electronics converter configuration used with a particular PMSG WECS a suitable MPPT controller is developed for its control.

\subsection{DC-Link Voltage Control}

For a PMSG wind turbine, the full power captured from the wind has to be transferred through the dc link and the GSC to the grid. This situation is different from that of a DFIG wind turbine. Because of this, control of the dc-link voltage is more challenging for a PMSG wind turbine than a DFIG wind turbine, especially when the conventional power control structure is used for the dc-link voltage control. However, when using the direct-power control structure for the GSC (see Fig. 3), high performance and fast dc-link voltage control can be obtained. Thus, control functions of the MSC and GSC can be decoupled effectively with the MSC responsible for maximum power extraction control and the GSC responsible for the dc link voltage control so that energy captured from the wind can be transferred to the grid while the dc- link voltage is stable.

\section{Software Implementation}

In this circuit, the adaptive MPPT controller and DPC technique is used to minimize the THD. The circuit operation is explained in the following points.

Uniform random number block is used as wind source to provide the input to the adaptive MPPT controller and PMSG. It is used to provide both steady and variable speed to the wind turbine (ie., it will change for every 0.05 seconds). The MPPT controller gets the wind sourceoutput and turbine speed as its input and is provided to the wind turbine characteristics. Thus it will get the optimum point such that the maximum power curve output will be greater than the recorded demanded output power and also provides the torque output to the PMSG. Torque is a force that causes something to spin around a central point, thus the rotor rotates. PMSG is designed such that it will provide five different outputs. They are rotor speed, electromagnetic torque, stator current, direct and quadrature axis currents. VI measurement block in MSC measures the stator torque and current and it is given to the PWM rectifier which converts AC to DC. DC link provides real and reactive power to both PWM rectifier and grid side inverter. It acts as common link and also as storage device. Thus the distortions produced in MSC are measured by FFT analysis method; it will be in an order of 24 to $11.29 \%$. So it must be reduced in GSC.

MSC gets stator voltage, rotor speed and turbine speed as three inputs and by using the DPC technique PI controller and PLL is used. PI controller is used to increase the speed of the response and to eliminate the steady state error. PLL is used to synchronize on a set of variable frequency. Thus the produced dq0 axis currents are transferred into abc transformation to produce PWM by using $\mathrm{dq}_{0}$ to $\mathrm{abc}$ transformation and PWM generator blocks.

The DC current is converted into AC by grid side inverter block. The coupled inductor is used to limit the flow of AC current to the grid. Here also produced stator voltage and current by the grid side inverter is measured by VI measurement block.

The GSC gets six input signals to control the total harmonic distortion finally. The inputs are PWM rectifier outputs, measured stator voltage and current, then finally output of coupled inductor. It works similar to MSC with PI controller and PLL and generates PWM output and provides the generated output to grid side inverter to convert as AC. Thus one of the problems in the production of electricity is distortions which is analyzed and reduced by MATLAB simulink method. The THD is reduced up to $1.42 \%$ which can be shown by using discrete power gui (FFT analysis).

Table 1.Parameter of the PMSG Wind Turbine 


\begin{tabular}{l|c|c}
\hline Parameter & Value & Units \\
\hline Generated rated power & 2500 & KVA \\
f(frequency) & 50 & $\mathrm{~Hz}$ \\
Generated rated voltage & 400 & $\mathrm{~V}$ \\
Stator resistance & 0.2 & p.u. \\
Stator leakage inductance & 0.02 & p.u. \\
Permanent magnet flux & 0.175 & p.u. \\
dc-link capacitor & 6.6 & $\mu \mathrm{f}$ \\
Grid-filter resistance & 1 & $\Omega$ \\
Grid-filter inductance & 0.05 & $\mathrm{H}$ \\
\hline
\end{tabular}

\section{Results and Discussion}

To evaluate the maximum power extraction, DC link voltage control, grid voltage support control of a PMSG wind turbine the optimal control strategy has introduced, an integrated simulation of a complete PMSG system including MSC and GSC is developed using DPC and detailed models in MATLAB simulink in which both steady and variable wind conditions are considered. In this chapter, obtained results are shown and discussed.

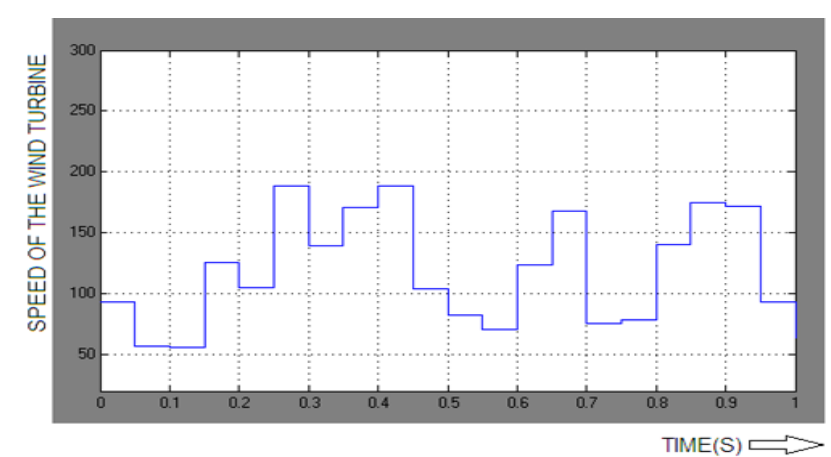

Fig.8. Wind Source Output

The wind source output which is varied for 0.05 seconds from 0 to 1 such that the turbine rotates at both steady and variable speeds as shown in Fig.8. After the system is settled, the output power is very close to the maximum power that can be captured by the turbine at the wind speed.

The rotor speed, electromagnetic torque, d-axis current, $\mathrm{q}$-axis current and a single phase $\mathrm{A}$ is taken from produced three phase stator currents as shown in Fig.9. The rotor speed increases linearly as the rotor starts to rotate. Electromagnetic torque produced by the PMSG is gradually decreased as shown in figure. $\mathrm{d}$-axis and q-axis currents also decreased, finally the stator current (a) can be measured with the limits $(10,-10)$ as peak to peak current in amps.

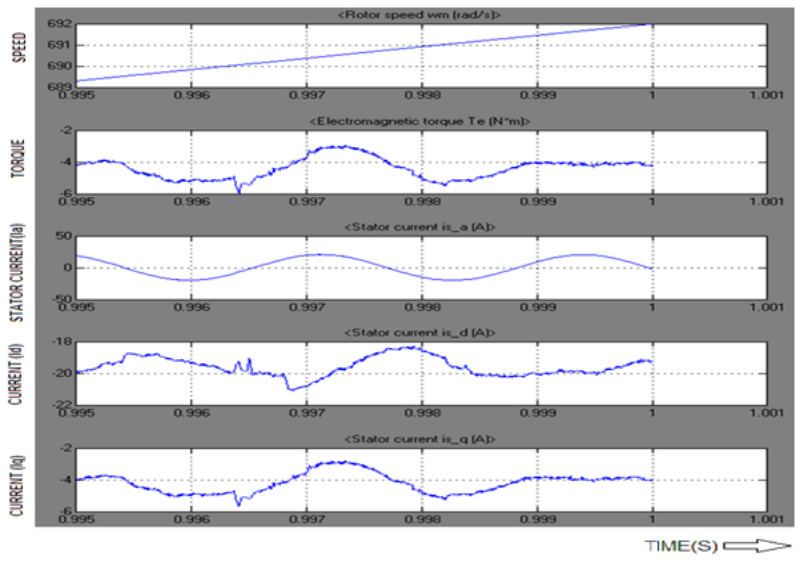

Fig.9. PMSG Output

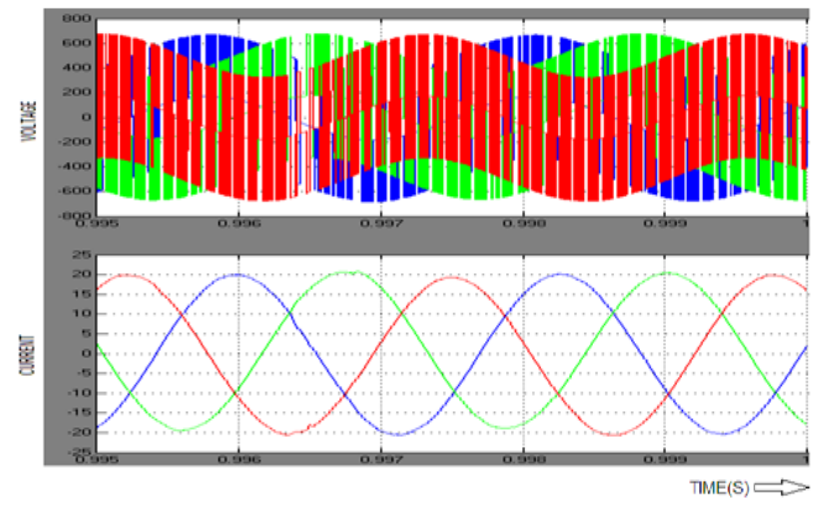

Fig.10.Voltage and Current Measurement for MSC Side

The Voltage and Current are generated by the rotation of PMSG as it gets the torque as input from Adaptive MPPT. This is used to measure 3 phase voltages and currents in a circuit. When connected in series with a three phase element, it return the three phase to ground voltages and line currents. This can output the voltages and currents in per unit values or in volts and amperes. The generated 3 phase stator voltage, stator current in MSC side are shown in fig 10.

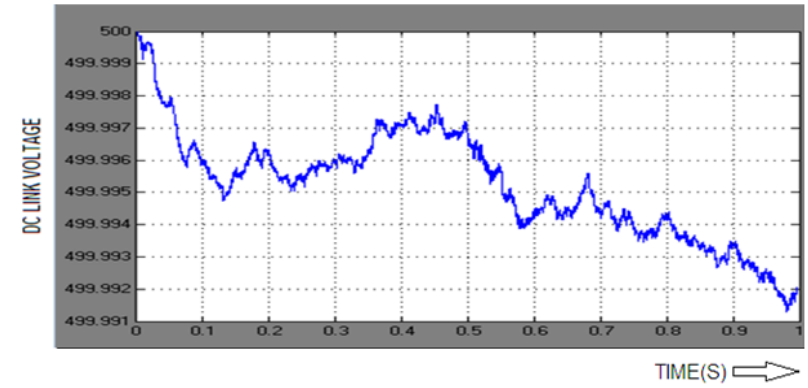

Fig.11.DC Link Output

For a simple voltage drop on the PCC bus more reactive power generation is needed to boost the PCC voltage. However, due to the rated current or converter PWM saturation constraint, GSC is unable to generate the required reactive power and it operates in the optimal control mode by maintaining the DC link voltage as the first priority (see fig.11). The dc-link voltage is kept almost constant under the optimal and DPC strategy, the operation of the synchronous generator and the maximum wind power extraction is nearly unaffected. 


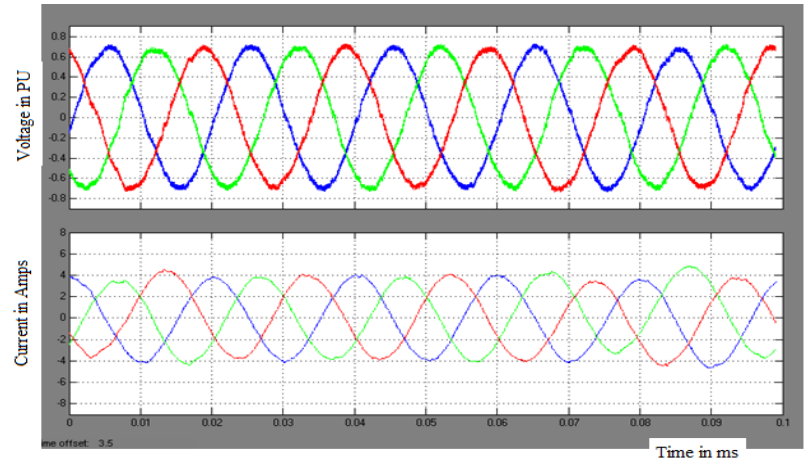

Fig.12. Voltage and Current Measurement for GSC Side

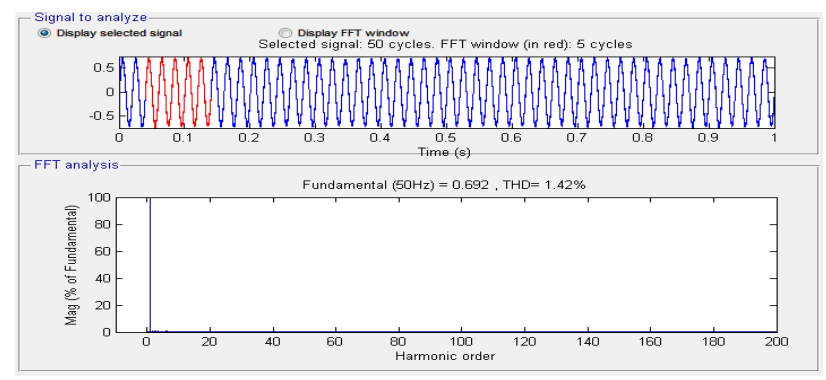

Fig.13. FFT Analysis Display(reduced THD in GSC)
The generated 3 phase stator voltages, stator currentsare shown in fig 12.which has similar operation as in MSC. In the fig 13.and the stator voltages in MSC and GSC are selected and the THD present in them are shown. From this figure we can clearly say that the THD in MSC is more which is reduced in the GSC.

\section{Conclusion}

This project presents the direct-power control designs for a PMSG wind turbine. This project shows how integrated MSC and GSC control is designed using direct-power control configurations to implement the maximum power extraction, DC link voltage control, grid voltage support controls and also how the distortions are reduced in the PMSG wind turbine. Comprehensive simulation studies demonstrates that a PMSG wind turbine, based on directpower control structure can effectively accomplish the wind turbine control objectives with superior performance within the physical constraints of the system under both steady and variable wind conditions. The proposed control approach operates in an optimal mode by controlling the MSC for maximum power extraction as the first priority and controlling the GSC to stabilize the DC link voltage as the main concern. Thus the proposed system shows the excellent performance and confirms the feasibility with less distortion level output $(1.42 \%)$.

\section{References}

1. R. Zavadil, N. Miller, A. Ellis, and E. Muljadi, "Making connections:Wind generation challenges and progress," IEEE Power Energy Mag., vol. 3, no. 6, pp. 26-37, Nov. 2005.

2. Z. Chen, J. M. Guerrero, and F. Blaabjerg, "A review of the state of the art of power electronics for wind turbines," IEEE Trans. Power Electron., vol. 24, no. 8, pp. 1859-1875, Aug. 2009.

3. S. J"ockel, "High energy production plus built in reliability-The new Vensys 70/77 gearless wind turbines in the 1.5 MW class," presented at the 2006 Eur.Wind Energy Conf., Athens, Greece, Feb. 27-Mar. 2, 2006.

4. Y. Chen, P. Pillary, and A. Khan, "PM wind generator topologies," IEEE Trans. Ind. Appl., vol. 41, no. 6, pp. 1619-1626, Nov./Dec. 2005.

5. H. Polinder, S.W. H. de Haan,M. R. Dubois, and J. Slootweg, "Basic operation principles and electrical conversion systems of wind turbines," presented at the Nordic Workshop Power Ind. Electron., Trondheim, Norway, Jun. 14-16, 2004.

6. G. Michalke, A. D. Hansen, and T. Hartkopf, "Control strategy of a variable speed wind turbine with multi-pole permanent magnet synchronous generator," presented at the 2007 Eur.Wind Energy Conf. Exhib., Milan, Italy, May 7-10, 2007.

A. Grauers, "Efficiency of three wind energy generator systems," IEEE Trans. Energy Convers., vol. 11, no. 3, pp. 650-657, Sep. 1996.

7. K. Tan and S. Islam, "Optimum control strategies in energy conversion of PMSG wind turbine system without mechanical sensors," IEEE Trans. Energy Convers., vol. 19, no. 2, pp. 392399, Jun. 2004.

8. F. Velenciaga and P. F. Puleston, "High-order sliding control for a wind energy conversion system based on apermanent magnet synchronous generator," IEEE Trans. Energy Convers., vol. 23, no. 3 , pp. 860-867, Sep. 2008.

9. North American Electric Reliability Corporation. (2009 Apr.)Accommodating High Levels ofVariable Generation [Online]. Available: www.nerc.com/files/IVGTF_Report_041609.pdf

10. Clipper Windpower, The Liberty $2.5 \overline{\mathrm{MW}}$ Wind Turbine:Clipper Design. (Dec. 2011). [Online].Available:http://www.clipperwind.com/productline.html
11. J. Belhadj and X. Roboam, "Investigation of different methods to control a small variable-speed wind turbine with PMSM drives," J. Energy Resources Technol., vol. 129, pp. 200-213, Sep. 2007.

12. M. Chinchilla, S. Arnaltes, and J. C. Burgos, "Control of permanent magnet generators applied to variable-speed wind-energy systems connected to the grid," IEEE Trans. Energy Convers., vol. 21, no. 1, pp. 130-135, Mar. 2006.

13. W. Qiao, L. Qu, and R. G. Harley, "Control of IPM synchronous generator for maximum wind power generation considering magnetic saturation," IEEE Trans. Ind. Appl., vol. 45, no. 3, pp. 1095-1105, Jun. 2009.

14. S. Li, T. A. Haskew, and L. Xu, "Conventional and novel control designs for direct driven PMSG wind turbines," Electr. Power Syst. Res., vol. 80, no. 3, pp. 328-338, Mar. 2010.

15. S. Li, T. A. Haskew, and Y. Hong, "PMSG maximum wind power extraction control using adaptive virtual lookup table approach in direct-current vector control structure," Int. J. Energy Res., vol. 35, no. 11, pp. 929-1022, Sep. 2011.

16. S. Li, T. A. Haskew, and L. Xu, "Control of HVDC light systems using conventional and direct-current vector control approaches," IEEE Trans. Power Electron., vol. 25, no. 12, pp. 3106-3118, Dec. 2010.

17. J. Matas, M. Castilla, J. M. Guerrero, L. Garcia de Vicuna, and J. Miret, "Feedback linearization of direct-drive synchronous windturbines via a sliding mode approach," IEEE Trans. Power Electron., vol. 23, no. 3, pp. 1093-1103, May 2008.

A. D. Hansen, P. Sørensen, F. Iov, and F. Blaabjerg, "Control of variable speed wind turbines with doubly-fed induction generators," Wind Eng., vol. 28, no. 4, pp. 411-432, Jun. 2004.

18. R. Bergen andV.Vittal, Power System Analysis, 2nd ed. Upper Saddle River, NJ: Prentice-Hall, 2000.

19. M. B. BanaSharifian, Y. Mohamadrezapour, M. Hosseinpour, and S. Torabzade, "Maximum power control of variable speed wind turbine connected to permanent magnet synchronous generator using chopper equipped with superconductive inductor," J. Appl. Sci., vol. 9, no. 4, pp. 777-782, 2009.

20. D. J. Bang, H. Polinder, G. Shrestha, and J. A. Ferreira, "Review of generator systems for direct-drive wind turbines," presented at the Eur. Wind Energy Conf. Exhib., Belgium, Mar. 31-Apr. 3, 2008. 
21. S. Heier, Grid Integration of Wind Energy Conversion Systems, 2nd ed. New York: Wiley, 2006.

22. N.W. Miller,W.W. Price, J. J. Sanchez-Gasca. (2003, Oct. 27). Dynamic modeling of GE 1.5 and 3.6 wind turbine-generators Version 3.0, Tech. Rep., GE Power Systems EnergyConsulting, Schenectady, NY, [Online].Available: www.easthavenwindfarm.com/filing/high/modeling.pdf 2012.
23. N. Mohan, Advanced Electric Drives-Analysis, Modeling and Control Using Simulink, Minnesota Power Electronics Research \& Education, MN, 2001.

24. R.KRISHNAN, Electric Motor Drives Modelling, Analysis and Control, Prentice Hall of India Private Limited, 2007, pp. 525-529. 